This item was submitted to Loughborough's Research Repository by the author.

Items in Figshare are protected by copyright, with all rights reserved, unless otherwise indicated.

\title{
Panel: Education on simulation model simplification - Beyond the rules of thumb
}

PLEASE CITE THE PUBLISHED VERSION

https://doi.org/10.1109/WSC.2018.8632544

PUBLISHER

(C) Institute of Electrical and Electronics Engineers (IEEE)

VERSION

AM (Accepted Manuscript)

LICENCE

CC BY-NC-ND 4.0

\section{REPOSITORY RECORD}

van der Zee, Durk-Jouke, Antuela A. Tako, Stewart Robinson, Paul Fishwick, and Oliver Rose. 2019. "Panel: Education on Simulation Model Simplification - Beyond the Rules of Thumb". figshare.

https://hdl.handle.net/2134/36817. 


\title{
PANEL: EDUCATION ON SIMULATION MODEL SIMPLIFICATION - BEYOND RULES OF THUMB
}

\author{
Durk-Jouke van der Zee \\ Faculty of Economics \& Business \\ University of Groningen \\ P.O. Box 800 \\ Groningen, 9700AV, THE NETHERLANDS
}

Paul Fishwick

The University of Texas at Dallas

Arts \& Technology

800 West Campbell Road, AT10

Richardson, TX 75080-3021, USA

\author{
Antuela Tako \\ Stewart Robinson \\ School of Business and Economics \\ Loughborough University \\ Loughborough \\ Leicestershire, LE11 3TU, UK
}

Oliver Rose

Department of Computer Science

Universität der Bundeswehr München

Werner-Heisenberg-Weg 39

Neubiberg, 85577, GERMANY

\begin{abstract}
Most management problems addressed by simulation studies can be characterized as complex and difficult to analyze. Simplification is instrumental in creating and employing simulation models that are useful - by focusing on those system elements that matter, and feasible - by reducing study efforts. Although simplification is considered a fundamental modelling activity, simulation educational support for mastering associated modelling skills is limited. Main textbooks either do not address this topic or tend to restrict their guidance to a few rules of thumb. This reflects how the topic of simulation model simplification is underdeveloped, despite the field of simulation being around 50 years of age. The purpose of this panel is to initiate a discussion about the way we teach simulation model simplification with the view to identifying improvements. This paper addresses the motivation for the panel, and presents panelists' "positions" about the way forward for education on simulation model simplification.
\end{abstract}

\section{INTRODUCTION}

Simplification is considered fundamental to modelling and simulation (Salt 1993; Shannon 1998). Model simplification can increase a model's utility by addressing its ease of use, flexibility, visualization, and run speed, as well as its feasibility in terms of time, resource and data needs (Robinson 2014). In these respects proper model simplifications contribute to analyzing and solving complex management problems. Clearly, a successful simulation study cannot do without simplification. Benefits associated with simple models, however, do not negate the need to build complex models on some occasions. The requirement is to build the simplest model possible, not simple models per se (Robinson 2008a). Simplification should always be justified by the model and evidence (Edmonds and Moss 2004), thereby safeguarding a satisfactory abstraction level.

Model simplification is not easy and it requires analysts to develop relevant skills for building models at an appropriate level of detail. Essential skills relate to key activities like recognizing the benefits of and need for simplification, identifying model components that may be simplified, and developing and validating simplifications. In performing activities, the analyst has to be able to cope with and address 
various drivers of model complexity, for example, problem size being (too) large (Morris 1967), unclear modelling objectives (Innis and Rexstad 1983), his/her own limitations with respect to domain knowledge (Nance et al. 1999), and common pitfalls like assuming model detail as inherently good for increasing realism (Chwif et al. 2000). Clearly, analysts need to be appropriately educated to undertake model simplification. In this panel session simulation educational support on model simplification will be addressed, by assessing the current situation and research needs. More specifically, we consider courses offered by academia.

This paper is structured as follows. In Section 2 we consider the motivation for this panel. Next, in Section 3 panel set up is discussed. In Section 4 panelists state their positions. Finally, in Section 5, we summarize main issues based on the position statements.

\section{MOTIVATION FOR THE PANEL}

After introducing the focus of this panel session, we now provide some observations from existing literature on model simplification that underlie the topic of this panel:

- Little attention: Many authors observe that model simplification has received little attention (Sevinc 1991; Chwif et al. 2000; Brooks and Tobias 2000; Robinson 2006; Van der Zee et al. 2011). They point at the low number of articles being published. This is confirmed in a recent review on approaches for simulation model simplification (Van der Zee 2017).

- Limited materials available for teaching: The lack of attention, see above, is mirrored in existing course books and materials, that tend to restrict their guidance to rules of thumb or do not address the issue at all. Exercises on model simplification are hardly found. Hence, the teacher is left on his/her own in educating students.

- Increasing industry needs: The ever increasing complexity of (new types) of operations systems like supply chains, transportation networks, health systems and advanced manufacturing systems suggest an even higher importance of model simplification for problem solving.

- Demands on simulation study set-up: The demands for shorter simulation study lead times increase relevance of model simplification (Chwif et al. 2006).

- Use of simulation resources: Progress made in simulation software and computer hardware is often erroneously used as an argument to build more detailed models, thereby neglecting possibilities for model simplification (Salt 1993; Chwif et al. 2000; Rank et al. 2016).

- Limited research on the topic: So far, model simplification does not seem to be on the research agenda of the simulation and modelling community. Apart from a number of authors targeting issues in isolation, structural support seems to be only available within semiconductor manufacturing and - to a lesser extent - within the community of researchers targeting simulation conceptual modelling. Starting from the high complexity of semiconductor manufacturing systems, a group of researchers works on a body of knowledge within their domain (Rose 2000; Rose 2007; Rank et al. 2016). Exploration of methods of model simplification has been identified as one of the research themes within the field of conceptual modelling (Van der Zee et al. 2011).

- Beyond craft: This session may be considered a follow up of recent panel discussions which stresses the need for research that aims to improve guidance on modelling - in an attempt to make it less of an art and more of a scientific discipline (Ehm et al. 2009; Van der Zee et al. 2010; Robinson et al. 2015). Typically, authors express the need for guidance by advocating a common choice of terminology, and by promoting the development of frameworks, strategies, principles, methods, standards, tools and criteria.

\section{PANEL DESCRIPTION}

We set up a panel, comprised of the following individuals: 
- Durk-Jouke van der Zee (University of Groningen)

- Antuela Tako (Loughborough University)

- Stewart Robinson (Loughborough University)

- Paul Fishwick (The University of Texas at Dallas)

- Oliver Rose (Universität der Bundeswehr München)

All panel members are asked to respond with a position paper to the following four questions:

1. What makes good education on simulation model simplification?

2. Is education on simulation model simplification currently good?

3. How could education on simulation model simplification be improved?

4. What should the Modeling and Simulation community do?

The questions are meant to facilitate an exploration of the state of play on education on simulation model simplification.

\section{POSITION STATEMENTS}

\subsection{Durk-Jouke van der Zee (University of Groningen)}

My experience is in educating undergraduate and postgraduate students, and research projects done in industry and health care.

\subsubsection{What Makes Good Education on Simulation Model Simplification?}

Simulation is a vehicle for decision support for the design of operations systems. Model simplification benefits quality of decision support by (i) allowing the analyst, engineering project team, and project stakeholders to focus on those system elements that matter - by leaving out those that don't, and (ii) improving feasibility of the simulation study by reducing costs of data collection, efforts put in modelling and coding, and speeding up experiments. Clearly, benefits of simplification are manifold and concern all key modelling activities, i.e., conceptual modelling, model coding, and experimenting. They may depend on the perspectives of the model users, given their specific roles within the project. Benefits are not for free, but come at a cost, as development and validation of proper simplifications involves efforts, time and resources (Frantz 1997).

Given the observed disadvantages of inappropriate model complexity, it makes sense to prevent models becoming too complex. This is clarified in the notion of evolutionary model design that advocates to start modelling with a simple model and next add relevant detail in an incremental way, compare, for example, Pidd (1999). The suggested approach is worthwhile, but still requires the analyst to consider model simplification in decision making on which system elements to represent in the model (Brooks and Tobias 2000).

What should a student learn about model simplification? Firstly, the student should know how and be able to do it. This sets requirements to his/her knowledge on relevant methods, techniques and insights, and his skills in applying this knowledge. At the same time a student should qualify as a good modeller, that seeks to avoid inappropriate model complexity.

What does it take to facilitate student education on model simplification? Foremost, education cannot do without a teacher who is both skilled and experienced. While courses may stress teacher skills, student projects in industry stress both skills and the teacher's knowledge of the craft - to guide the student in model simplification. Ideally, simplification is introduced and exercised in courses starting from text books and associated materials that familiarize students with step wise approaches that (i) assist in performing a cost-benefit analysis of possible model simplifications, (ii) organize the process of simplification by identifying and detailing key activities like tracing inappropriate complexity, and developing and validating 
model simplifications, and (iii) facilitate the process of simplification by suggesting the use of principles, methods, good practices and tools. More in general, students' modelling skills should be fostered by making them aware of complexity drivers and ways to deal with them, thereby - ideally - preventing inappropriate model complexity.

\subsubsection{Is Education on Simulation Model Simplification Currently Good?}

No. In my experience model simplification hardly gets any attention in simulation courses, thereby mirroring course books and materials, that do not really address the issue because of a lack of research. Thinking over model complexity is usually not propagated. The use of toy size models during courses may contribute to this. Probably, students only encounter the need for model simplification in doing simulation projects in industry, relating to systems of sufficient complexity. The rising interest for conceptual modelling has improved this situation a bit, by acknowledging the need for considering simplification in determining model content (Robinson 2008b). However, apart from this acknowledgement, little support is provided.

\subsubsection{How Could Education on Simulation Model Simplification be Improved?}

Building on the above observations, education on model simplification is in great need of teaching materials that (i) clarify the notion of model simplification and its meaning for model utility and feasibility, (ii) offer step wise approaches for organizing the process of model simplification, (iii) suggest proper principles, methods, good practices and tools that facilitate model simplification, (iv) define criteria on whether to simplify, and (v) foster awareness of drivers of model complexity. Furthermore, exercises on model simplification preferably relate to systems of sufficient complexity, and should include a cost-benefit analysis, starting from the various perspectives of the model users.

\subsubsection{What Should the Modeling and Simulation Community Do?}

Surprisingly, simulation model simplification is a green field and has been this for many decades. Clearly, some contributions have been made over the years relying on the efforts of individual authors. As a net effect a fragmented landscape can be observed, which lacks a frame of thinking. The field of the semiconductor manufacturing may be considered an exception. Within this field support is substantial, relying on a group of researchers of relevant size, that unite in addressing the large complexity of systems faced along research lines.

Undisputedly, there is a need for more research on simulation model simplification. The route taken by a group of researchers on conceptual modelling may serve as an example (Robinson et al. 2011). Starting around 2006 the group undertook joint initiatives concerning presence at major simulation conferences (dedicated sessions, tutorials), focused workshops, journal special issues, and a first book on the subject (Robinson et al. 2011). As a net effect conceptual modelling now holds a firm position on the communities' research agenda. In this way the community contributes to the buildup of a relevant knowledge base that serves as a basis for developing teaching materials.

\subsection{Antuela Tako (Loughborough University)}

\subsubsection{What Makes Good Education on Simulation Model Simplification?}

The aim of education is ultimately to prepare students to apply skills gained from education in their professional careers. From my experience of working in health care type problems, I come across two main types of model simplification activities, which I think should be also taught: 1) reducing the problem scope and 2) simplifying the model content. The first activity involves identifying the parts of the system the model should include while designing the conceptual model, guided by the model objectives. The second activity involves mostly technical modifications to represent parts of the computer model in simpler ways, 
such as for example replacing two or more activities by one, whereas the time to complete those activities is represented by a statistical distribution. They are introduced due to lack of data availability or because we are interested in simpler models that are faster to develop and/or easier to communicate to the clients, which is often the case in facilitated modelling (Robinson et al. 2014; Tako and Kotiadis 2015). Learning to do these two activities successfully is important for someone who chooses to take a professional career in simulation modelling. However, introducing model simplifications does not come natural to novice modellers.

Learning to reduce the problem scope is more intuitive and conceptually more difficult to grasp by novice modellers, but an important general skill to have as a modeler. Existing conceptual modelling frameworks can be used to guide the modeler through the process of deciding what to include and/or exclude into their simulations. I personally find useful adopting problem structuring methods tools. The PartiSim approach (Tako and Kotiadis 2015) for example, includes tools adapted from soft systems methodology (SSM) (Checkland 1999) in the modelling process. More specifically, the conceptual modelling toolset can be used to arrive at the model objectives and then to define the model scope (see PartiSim toolset 3: Define Conceptual Model). Students can be taught through these tools and then let to practice using a simplified case study.

Simplifying the model's content, involves more technical tricks that seasoned modelers develop with experience. This can be taught through example models showcasing existing methods. The learning cycle can be completed by practicing through hands-on individual or group exercises in lab sessions and coursework assignments.

Model simplification skills would be best suited to teach through hands-on exercises that provide the students or novice modellers the opportunity to learn through practice, that is what Kolb calls experiential learning experience (Kolb 1984). Model simplification can be taught progressively throughout the curriculum, where students first start with solving smaller, more defined modelling exercises and then move on to wider and less defined problems.

\subsubsection{Is Education on Simulation Model Simplification Currently Good?}

Considering $M \& S$ education, especially in business education that I have experience of, the main aim is to teach the students to appreciate the role of using simulation models in business and to learn to build simple simulation models on the computer. We do not place much emphasis on teaching students how to build simpler models. However, the message "keep the model simple" runs throughout the course (Pidd 2003).

There are challenges to teaching simulation model simplification as I consider it to be an advanced skill. Learning simulation modelling involves a number of skills, such as model coding, statistical analysis, experimental design, which makes M\&S courses quite demanding. Furthermore, as students do not have prior experience of simulation, only basic modelling skills can be taught. As a result there is limited time in the course to dedicate on model simplification. Another problem, deriving from its own nature of education, is that we teach simulation based on simplified problems. In educational settings students are often asked to build models of already pre-defined problem/settings, where the tutor or examples available on existing textbooks, have already gone through a process of simplification. Hence, student rarely get the opportunity to define the scope of the problem.

\subsubsection{How Could Education on Simulation Model Simplification be Improved?}

Considering the current education on model simplification, I believe that model simplification can be only taught at a basic level on UG or PG masters' level courses, which can be later on advanced through experience in practice and real life projects. Education on model simplification could be improved, through one or more of the following:

- Use example models and exercises that illustrate model simplification methods and give novice modelers the opportunity to review, reflect and learn from their experience. 
- Provide students with real life examples and mini projects to experience model simplification in practice.

- Ensure that students have the opportunity to learn problem structuring skills such as soft systems methodology (Checkland 1999) in the educational curriculum which can help make sense of and define the scope of complex problems.

- Include model simplification in assessment criteria and feedback.

\subsubsection{What Should the Modeling and Simulation Community Do?}

In my opinion the M\&S community should consider the following:

- More research on the topic that can help modellers make informed choices about the level of complexity (or simplicity) included in their models. To this date there are no agreed measures to determine model complexity (Wang and Brooks 2007; Ahmed and Shah 2015). We are currently studying the effect of using two different levels of model simplifications on users' learning (Tsioptsias et al. 2018) and find that there is a need for more research on this topic.

- Develop guidelines for model simplification that can be adapted to teach not only students taking $\mathrm{M} \& S$ courses, but also practitioners, making modelling less of a craft.

- Share case studies and example models illustrating model simplification. Both practitioners and academics should join forces to share practice and to learn from each other.

\subsection{Stewart Robinson (Loughborough University)}

My experience is in educating undergraduate and postgraduate students, and in training practitioners working in business and the public sector. I have drawn on this experience in forming the discussion below.

\subsubsection{What Makes for a Good Education on Simulation Model Simplification?}

In simple terms (which seems appropriate for this discussion!), a good education on simulation model simplification would achieve the learning outcome that modelers build simpler models. In particular, they would be able to build the simplest model possible to achieve the objectives of a simulation study. This could better be achieved by effectively teaching modeling principles, conceptual modeling frameworks and simplification methods.

The overarching modeling principle is as stated above: build the simplest model possible to achieve the modeling objectives. Robinson (2014) illustrates this with the graph in Figure 1. This demonstrates the relationship between model accuracy and model complexity. Increasing levels of complexity tend to increase the accuracy of a model with diminishing returns, and never achieving 100\% accuracy. Eventually, too much complexity can lead to a less accurate model as the knowledge and data required to support such a model are not available.

Beyond this overarching principle, it is useful to teach a set of general principles such as: focus on the decision, not the system; abstract - do not model all you know about the world; the model should drive the data requirements and not the available data drive the model; start small and add. For a discussion of modeling principles see Powell (1995) and Pidd (1999).

Conceptual modeling frameworks aim to help a modeler make good choices in determining what to model and what not to model. Although they do not provide specific guidance on choosing model simplifications, they do encourage a modeler to think through options for model simplification. Examples of these frameworks include Robinson (2008b) and Arbez and Birta (2016). 
Van der Zee, Tako, Fishwick, Robinson, and Rose

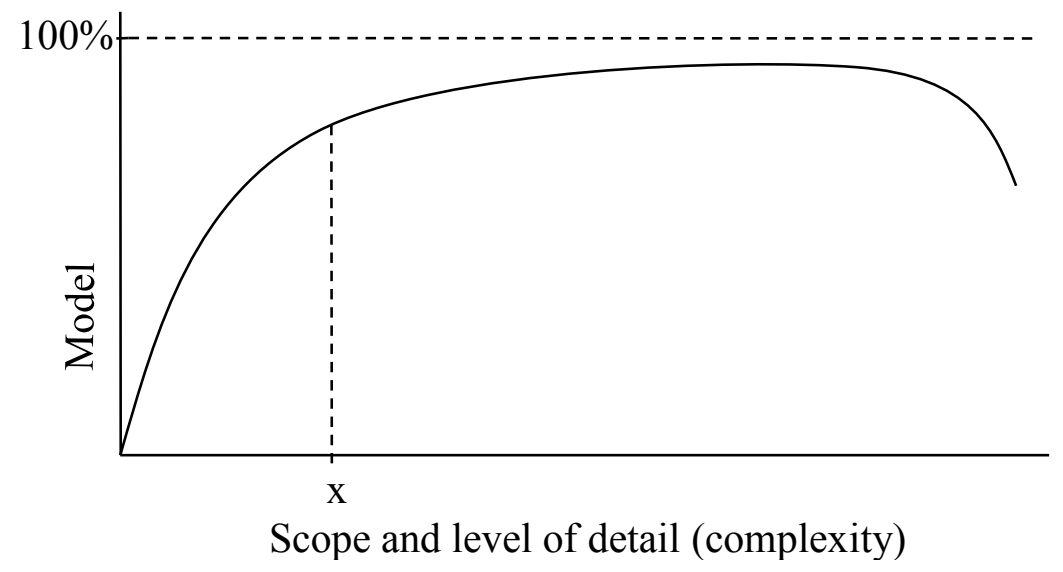

Figure 1: Model accuracy and model complexity (Robinson 2014).

At the third level it is useful to teach specific model simplification methods. These provide a set of ideas for how to model systems more simply. For instance, the use of 'black-box modeling', in which a section of a system is simplified to be represented as a time delay (Robinson 2014). Figure 2 illustrates the approach. As an entity $X_{i}$ enters the black-box, the time at which it is due to leave, $t_{i}$, is calculated. When the simulation reaches time $t_{i}$, the entity leaves the box. Discussions on model simplification methods can be found in Morris (1967), Courtois (1985), Zeigler (1976), Innis and Rexstad (1983), Yin and Zhou (1989), Robinson (1994) and Frantz (1995).

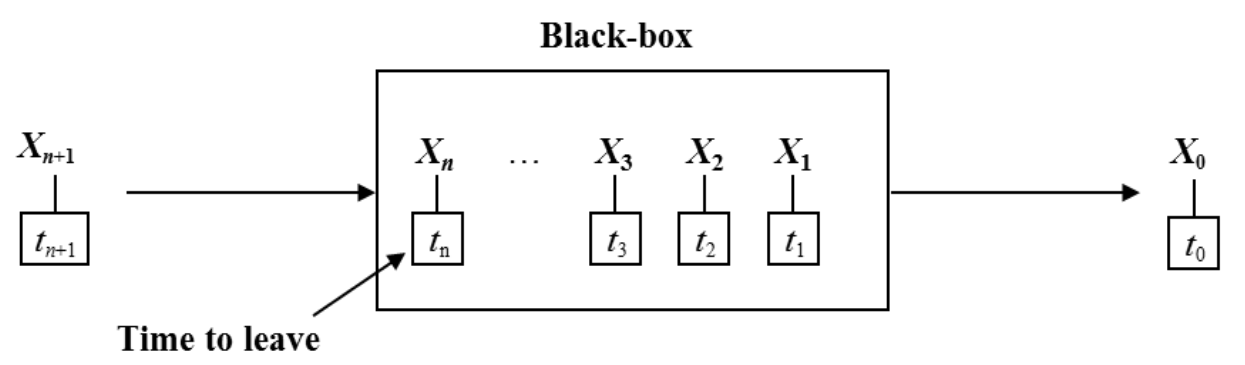

Current simulation time $=t_{0}$

Figure 2: Black-box modeling (Robinson 2014).

\subsubsection{Is Education on Simulation Model Simplification Currently Good?}

Put succinctly, the answer is "no." My experience is that most simulation courses for students and practitioners focus on software skills and analysis skills. There is little or no focus on model simplification and conceptual modeling more generally. This is probably because most educators were themselves just taught software and analysis skills. Further, it is more difficult to teach the 'craft' of modeling and less natural for the more scientifically minded to do so.

It would probably be easiest to teach model simplification through a set of simplification methods, but this is an area which is very underdeveloped. Note the dates of the articles on model simplification methods listed above. Despite a long history going back to 1967, there does not appear to have been any appreciable work on this topic in this century! 
Van der Zee, Tako, Fishwick, Robinson, and Rose

\subsubsection{How Could Education on Simulation Model Simplification be Improved?}

Model simplification, and conceptual modeling more generally, should become a mainstream topic in all simulation courses and in all educational materials including simulation books. There should always be a presentation on modeling principles, conceptual modeling frameworks and simplification methods, followed by associated practice exercises and assessments.

\subsubsection{What Should the Modelling and Simulation Community Do?}

The community should develop educational material on modeling principles, conceptual modeling frameworks and simplification methods. This will require a renewed research effort, especially up-to-date research on model simplification methods. These materials should be supported by exercises and assessments that would teach model simplification skills. As an example, see the Happy Faces Daycare conceptual model challenge (Loper et al. 2012). It would also be useful to provide examples of real life projects which involve model simplifications; see, for instance, the outpatients clinic problem (Robinson 2015). These are both motivational and explanatory. Indeed, they could provide the basis for identifying and forming a taxonomy of simplification methods.

\subsection{Paul Fishwick (The University of Texas at Dallas)}

My experience in the area of model simplification is based on my (1) early work in industry (NASA Langley Research Center) and Newport News Shipbuilding, (2) formative academic career at the University of Florida from 1986-2012 and more recently, (3) interdisciplinary career spanning two schools (Engineering and Computer Science, Arts, Technology \& Emerging Communication) at the University of Texas at Dallas. The interdisciplinary nature of my current work has encouraged me to take a broad world view of modeling and simulation, spanning different parts of the academy.

\subsubsection{What Makes for a Good Education on Simulation Model Simplification?}

"Good education" depends on educational learning objectives and the target group of learners. If one is situated within a particular university school, these objectives and the learners tend to be specific. For instance, in a Management Science Department, most learners are probably management science majors and the learning objectives are going to be model types and analyses appropriate for these majors.

The question of educational objectives becomes more complicated when we consider a general concept of model that is independent of vocation or speciality. Consider that the model in question is a hurricane (or typhoon) wind model. This model may be used to assess future risk for a set of geographically-situated properties. Who is the audience for such a model? For the computer scientists writing the code to implement the model, there are a number of simplifications possible, including the specifications in software engineering. These diagrammatic representations based perhaps on the Unified Modeling Language (UML) (Fowler 2003) have built-in approaches to simplification based on loose ideas inherent within natural language. To create a simplified model in UML is to use simpler categories and concepts. There are concepts at different levels for the hurricane simulation: (1) a high level such as "wind field" with an average speed intensity integrated over time, or (2) a low level such as "wind field within County X at Time Y". These simplifications are a combination of everyday language, and also specialized languages for meteorology. Perhaps the best approach to model simplification, generally speaking, is to understand how natural and professional languages deal with modeling, and model attribute, abstractions. The question of abstraction permeates all disciplines (Fishwick 1989). The question is how deep, or how high, to go?

\subsubsection{Is Education on Simulation Model Simplification Currently Good?}

All education is good but can be improved depending on the goals of the education. If a goal of the societies for modeling and simulation wish to expand and integrate beyond our current confines, then we may need 
to broaden the discussion of simplification. Model simplification is an artifact of abstraction, which is a more general word.

We should also consider movements in both directions: from abstract to concrete and vice versa. The idea of model simplification as a phrase suggests that a model already exists, and we wish to simplify that model. But an engineering approach would be to assume that we begin with preliminary, abstract design and then gradually refine our terms and model components to be less abstract, and more concrete. This process may involve many steps, each step with different abstraction levels.

\subsubsection{How Could Education on Simulation Model Simplification be Improved?}

The education can be improved in the following ways:

- Model simplification is a form of the abstraction-specification dualism and should be enhanced as a subject to incorporate proceeding in both directions.

- Model simplification can begin with natural language, and then proceed to refined vocabularies (e.g. professional languages), and basic design in the form of drawing. The ideas behind writing and drawing come from the liberal and fine arts, and so an appropriate integration is required to move model simplification into a wider arena.

Fishwick (2017) introduced the idea of dividing modeling into three categories: Knowledge, Space, and Time. Knowledge models (Sowa 1983; Davis et al. 1993) are rooted in natural language to the point where a natural language essay can be thought of as providing a simplification of a scene or behavior-a model. If one is to describe a model to a more general audience, it is necessary to speak the language of the audience. Knowledge is formally captured in the mathematical subjects of set theory and logic. Set theory is not only the core of modern mathematics; it is also a basis for formal logic, upon which we might draw diagrams such as state and event graphs, semantic networks, concept maps, and mind maps. These diagrams and maps are visual tools for expressing set theory and logic. The area in Computer Science termed data structures is also relevant when describing knowledge. Model simplification of Knowledge models comes from natural language categories. These categories can be expressed in logic, or in extensions such as object-oriented design.

Space modeling (Encarnacao et al.1990) revolves around specifying geometry either in terms of physical object shapes or how 2D or 3D space is partitioned. Model simplification of space modeling is usually oriented around spatial aggregation and level of detail. A factory contains floors, each floor has specific work areas, and each work area has specific machinery. Time modeling (Fishwick 2007) is to create a model that reflects change in state and event over time. Most model simplification in time modeling leverages natural language categories. For example, the state of a machine might be "in operation" but this state has sub-states, which in turn, have their own sub-states (Fishwick 1994).

We need to examine this triad (Knowledge, Space, and Time) with respect to the history of modeling and simulation. Traditionally, in the Winter Simulation Conference, we are a community concerned with discrete event (time-based) simulation. Issues of knowledge and space would seem out of place. However, in the case of conceptual modeling, there has been a resurgent interest at the turn of the $21^{\text {st }}$ century. This resurgence is linked to the older work in Artificial Intelligence where conceptual modeling has been ongoing work since the 1960s (Sowa 1983). As far as space and geometry, the fast changes in semiconductor technology have allowed portable phones to display real-time 3D geometry. With such enhanced speed, some vendors have built models that are as much geometric as they are time-based. If our models now include "things" that have shape, then our model simplifications must move behind temporal abstractions. 
Van der Zee, Tako, Fishwick, Robinson, and Rose

\subsubsection{What Should the Modelling and Simulation Community Do?}

The modelling and simulation community has a good foothold in model abstraction and model simplification (Morris 1967; Zeigler 1976; Fishwick 1994; Robinson 2015; Robinson et al. 2015). What the community should do depends on whether there is sufficient interest in expanding beyond the borders of the current community. Virtually every academic subject involves the ideas of simplification, specification, and abstraction. If we are going to either grow or interconnect with other communities, then we need to better understand how these other communities think of simplification. In many cases, our collective ideas may be similar. The ideas may differ only at ground level where the specialized modeling communities exist and flourish.

\subsection{Oliver Rose (Universität der Bundeswehr München)}

My background is in teaching statistics and simulation for undergraduate and postgraduate computer science students and practitioners from industry and the military. Our research is focusing on a variety of production industries and military logistics.

\subsubsection{What Makes for a Good Education on Simulation Model Simplification?}

First, I would like to define what simple in the context of simulation modeling means to me: the model is easy to understand for all participating stakeholders of a simulation project and there will be no communication problems among all stakeholders about the model. Starting from this very simple (sic!) definition simulation model simplification has two main aspects: (1) keeping the mental system modeling concept simple, and, (2) keeping the simulation model communication simple. Of course, both aspects are very closely related.

Coming originally from queueing theory applied to analyze the performance of computer networks, I experienced that starting from queueing models is a rather comprehensive but not oversimplifying concept for simulation modeling. It is very easy to understand the concept of limited resources and the fact that jobs, customers, etc. queue up if all resources are currently in use. In addition, it is very straightforward to build networks consisting of queue and resource components representing the flow of items through a (for instance, production or logistics) system. All sorts of decisions which have to be taken in that system, such as job sequencing, resource dispatching or route selection, come into play very naturally, too.

The second aspect, simple model communication, is also very important. Over the last decade, there was a lot of research about the appropriate way to describe simulation models, in particular, the conceptual models. All co-authors of this paper spent a considerable amount of their time and effort to convince their students and their colleagues that (if you get the problem description right) conceptual modeling is the most important simulation project phase to obtain a simple model. In order to keep the model communication simple, I experience that simple diagrams about state changes of structural simulation model components (similar to the UML state machine diagrams) and simple networks of activities to represent the processes which deal with the model components (similar to the UML activity diagrams) have the appropriate level of simplicity while facilitating the communication about models in simulation project teams. This is true for project team members with basically arbitrary academic and non-academic backgrounds.

\subsubsection{Is Education on Simulation Model Simplification Currently Good?}

My personal experience does not lead to a clear conclusion about the right answer to that question. In contrast to the introductory statement of our paper, I am rather optimistic that despite the lack of a large body of research in simulation model simplification it is not too complicated to teach it for an experienced instructor. 


\subsubsection{How Could Education on Simulation Model Simplification be Improved?}

I think, it would be a good idea to teach queueing theory basics to all simulation students. This methodology forms the basis of a very simple and comprehensive mental model for all production, logistics, and service systems most analysts in our community are interested in. In addition, the students should be taught at least one general purpose system description language like SysML or UML. Apart from that it should be made very clear that the origin for a simple model is always a structured problem description because only then the modeler can decide what has to be modeled and at which level of detail. Both decisions are very important for model simplicity.

Table 1: A SWOT analysis of education on simulation model simplification representing the positions of this paper.

\section{Strengths}

- Agreement that education on simulation model simplification is required and needed

- Research in semiconductor manufacturing

- Recognition of relevance of model simplification for conceptual modelling

- Good education on model simplification is very well possible

\section{Weaknesses}

- Use of simple/simplified size models in education, that hinders students getting confronted with reallife systems complexity and dealing with problem size.

- A main focus on software and analysis skills in simulation courses, leaving (time-wise) little room for model simplification.

- Dependency on the teacher's skills with respect to model simplification, and his willingness to address the issue - as it may be less natural for the more scientifically minded to do so.

- Lack of a wider (curriculum) perspective on model simplification that includes various other modelling techniques - which may benefit simulation model simplification.

- Lack of text books, supportive materials, and exercises.

- Simplification methods being underdeveloped.

- Little overview and insights on the way model simplification influences essential model qualities - which are likely not the same for all stakeholders.

\section{Opportunities}

- Develop modelling principles, modelling frameworks, simplification methods and tools.

- Develop exercises on model simplification, including relevant assessment criteria - relating to (real-life) systems of sufficient complexity

- Use and share insights from other fields outside M\&S - concerning various categories of modelling techniques - that may support alternative disciplines.

- Publish research, possibly "hosted" by fields addressing simulation conceptual modelling, and semiconductor manufacturing.

- Share case-studies and example models illustrating simulation model simplification.

\section{Threats}

- Modelling being considered an art

- Small research base

- Research efforts being scattered over application domains and disciplines. 
Van der Zee, Tako, Fishwick, Robinson, and Rose

\subsubsection{What Should the Modelling and Simulation Community Do?}

Our community should stop talking about modeling as an art. Of course, models become better and simpler the more experience a modeler has. On the other hand, there are more than enough textbooks, courses, guides, best practices, etc. about the basic principles of good modeling (see alone the references of this paper) that we should rather talk about modeling as an engineering task and set up research accordingly.

\section{SUMMARY}

This paper facilitates an exploration of the state of play on education on simulation model simplification by inviting 5 researchers to put their views on this field. They do so by answering a set of questions. Not surprisingly, in accordance with their various backgrounds, their answers are multi-facetted. In an attempt to arrive at some overarching conclusions from their positions we summarize the most frequent themes that come up in the format of a SWOT (Strengths, Weaknesses, Opportunities and Threats) analysis (Table 1).

\section{ACKNOWLEDGMENTS}

The authors thank two anonymous reviewers for their detailed comments and helpful suggestions.

\section{REFERENCES}

Ahmed, R., and M. H. Shah. 2015. "Exploring the Context and Practices of Expert Simulation Modellers". International Journal of Simulation Modelling 14(2):265ᄀ277.

Arbez, G., and L. G. Birta. 2016. "Tutorial on ABCmod: An Activity Based Discrete Event Conceptual Modelling Framework." In Proceedings of the 2016 Winter Simulation Conference, edited by T. M. K. Roeder et al., 88-102. Piscataway, New Jersey: IEEE.

Brooks, R.J. and A. M. Tobias. 2000. "Simplification in the Simulation of Manufacturing Systems". International Journal of Production Research 38(5):1009-1027.

Checkland, P. 1999. Systems Thinking Systems Practice. Chichester: Wiley.

Chwif, L., M. R. P. Barretto, and R. J. Paul. 2000. "On Simulation Model Complexity". In Proceedings of the 2000 Winter Simulation Conference, edited by J. A. Joines et al., 449-455. Piscataway, New Jersey: IEEE.

Chwif, L., R. J. Paul, and M. R. P. Barretto. 2006. "Discrete Event Simulation Model Reduction: A Causal Approach". Simulation Modelling Practice and Theory 14(7):930-944.

Courtois P. J. 1985. "On Time and Space Decomposition of Complex Structures." Communications of the ACM 28(6):590-603.

Davis, R., H. Shrobe, and P. Szolovits. 1993. "What is Knowledge Representation?”. AI Magazine 14(1): 17-33.

Edmonds, B., and S. Moss. 2004. "From KISS to KIDS - An 'Anti-simplistic' Modelling Approach". In International Workshop on Multi-Agent Systems and Agent-Based Simulation (MABS 2004), Lecture Notes in Computer Science book series (LNCS, volume 3415). New York: Springer.

Ehm, H., L. McGinnis, and O. Rose. 2009. “Are Simulation Standards our Future?". In Proceedings of the 2008 Winter Simulation Conference, edited by M. D. Rossetti et al., 1695-1702. Piscataway, New Jersey: IEEE.

Encarnacao, J. L., R. Lindner, and E. G. Schlechtendahl. 1990. Computer Aided Design: Fundamentals and Systems Architectures. Berlin: Springer Verlag.

Fishwick, P. A. 1989. "Abstraction Level Traversal in Hierarchical Modeling". In Modelling and Simulation Methodology: Knowledge Systems Paradigms, edited by B. P. Zeigler, M. Elzas, and T. Oren, 393-429. New York: Elsevier.

Fishwick, P. A. 1994. Simulation Model Design and Execution: Building Digital Worlds. Upper Saddle River, New Jersey: Prentice Hall. 
Van der Zee, Tako, Fishwick, Robinson, and Rose

Fishwick, P. A. 2007. Handbook of Dynamic System Modeling. Boca Raton: CRC Press, Chapman \& Hall. Fishwick, P. A. 2017. "Modeling as the Practice of Representation." In Proceedings of the 2017 Winter Simulation Conference, edited by W. K. V. Chan et al., 4276-4287. Piscataway, New Jersey: IEEE.

Fowler, M. 2003. UML Distilled Third Edition: A Brief Guide to the Standard Object Modeling Language. Boston: Addison-Wesley Professional.

Frantz, F. K. 1995. "A Taxonomy of Model Abstraction Techniques." In Proceedings of the 1995 Winter Simulation Conference, edited by C. Alexopoulos et al., 1413-1420. Piscataway, New Jersey: IEEE.

Frantz, F. K. 1997. “Analyzing Models for Abstraction”. In Proceedings of SPIE, Enabling Technology for Simulation Science, 22-24 April 1997, Orlando, Florida, Volume 3083, edited by A. F. Sisti, 14-21. Orlando, Florida: SPIE.

Innis, G., and E. Rexstad. 1983. "Simulation Model Simplification Techniques". Simulation 41(1):7-15.

Kolb, D. A. 1984. Experiential Learning: Experience as the Source of Learning and Development. Englewood Cliffs, New Jersey: Prentice-Hall.

Loper, L. L., L. G. Birta, and G. Arbez. 2012. "Lessons from a Conceptual Modeling Exercise.” In Proceedings of the 2012 Winter Simulation Conference, edited by C. Laroque et al., 3735-3746. Piscataway, New Jersey: IEEE.

Morris, W. T. 1967. “On the Art of Modeling”. Management Science 13(12): B707-B717.

Nance, R. E., C. M. Overstreet, and E. H. Page. 1999. "Redundancy in Model Specifications for Discrete Event Simulation". ACM Transactions on Modeling and Computer Simulation 9(3):254-281.

Pidd, M. 1999. "Just Modeling Through: a Rough Guide to Modeling." Interfaces 29(2):118-132.

Pidd, M. 2003. Tools for thinking. Modelling in Management Science. 2nd ed. Chichester: Wiley.

Powell. S. G. 1995. "Six Key Modeling Heuristics." Interfaces 25(4):114-125.

Rank, S., C. Hummel, T. Schmidt, J. Müller, A. Wenzel, R. Lasch, and G. Schneider. 2016. "The Correct Level of Model Complexity in Semiconductor Fab Simulation-Lessons Learned from Practice". In Proceedings of the 27th Annual SEMI Advanced Semiconductor Manufacturing Conference (ASMC) Saratoga Springs 16-19 May 2016, 133-139. Saratoga Springs, New York: IEEE.

Robinson, S. 1994. "Simulation Projects: Building the Right Conceptual Model." Industrial Engineering 26(9):34-36.

Robinson, S. 2006. "Conceptual Modeling for Simulation: Issues and Research". In Proceedings of the 2006 Winter Simulation Conference, edited by L. F. Perrone et al., 792-800. Piscataway, New Jersey: IEEE.

Robinson, S. 2008a. "Conceptual Modelling for Simulation Part I: Definition and Requirements." Journal of the Operational Research Society 59(3):278-290.

Robinson, S. 2008b. "Conceptual Modelling for Simulation Part II: A Framework for Conceptual Modelling." Journal of the Operational Research Society 59(3):291-304.

Robinson, S., R. Brooks, K. Kotiadis, and D.J. van der Zee, Eds. 2011. Conceptual Modeling for Discrete Event Simulation. Boca Raton: CRC Press.

Robinson, S. 2014. Simulation - The Practice of Model Development and Use. $2^{\text {nd }}$ ed. London: Palgrave.

Robinson, S., C. Worthington, N. Burgess, and Z. J. Radnor. 2014. "Facilitated Modelling with Discrete Event Simulation: Reality or Myth?”. European Journal of Operational Research 234(1):231-240.

Robinson, S. 2015. "A Tutorial on Conceptual Modeling for Simulation." In Proceedings of the 2015 Winter Simulation Conference, edited by L. Yilmaz, et al., 1820-1834. Piscataway, New Jersey: IEEE.

Robinson, S., G. Arbez, L. G. Birta, A. Tolk, and G. Wagner. 2015. "Conceptual Modeling: Definition, Purpose and Benefits". In Proceedings of the 2015 Winter Simulation Conference, edited by L. Yilmaz et al., 2812-2826. Piscataway, New Jersey: IEEE.

Rose, O. 2000. "Why do Simple Wafer Fab Models Fail in Certain Scenarios?". In Proceedings of the 2000 Winter Simulation Conference, edited by J. A. Joines et al., 1481-1490. Piscataway, New Jersey: IEEE.

Rose, O. 2007. "Improved Simple Simulation Models for Semiconductor Wafer Factories". In Proceedings of the 2007 Winter Simulation Conference, edited by S. G. Henderson et al., 1708-1712. Piscataway, New Jersey: IEEE. 
Salt, J. D. 1993. "Keynote Address: Simulation Should Be Easy and Fun!”. In Proceedings of the 1993 Winter Simulation Conference, edited by G. W. Evans et al., 1-5. Piscataway, New Jersey: IEEE.

Sevinc, S. 1991. "Theories of Discrete Event Model Abstraction". In Proceedings of the 1991 Winter Simulation Conference, edited by B. L. Nelson et al., 1115-1119. Piscataway, New Jersey: IEEE.

Shannon R. E. 1998. "Introduction to the Art and Science of Simulation." In Proceedings of the 1998 Winter Simulation Conference, edited by D.J. Medeiros et al., 7-14. Piscataway, New Jersey: IEEE.

Sowa, J. F. 1983. Conceptual Structures: Information Processing in Mind and Machine. The Systems Programming Series, Boston: Addison-Wesley Publishing.

Tako, A. A., and K. Kotiadis. 2015. "PartiSim: A Multi-methodology Framework to Support Facilitated Simulation Modelling in Healthcare". European Journal of Operational Research 244(2):555-564.

Tsioptsias, N., A. A. Tako, and S. Robinson. 2018. "Can we Learn from Wrong Simulation Models? A Preliminary Experimental Study on User Learning." In Proceedings of the 2018 Operational Research Society Simulation Workshop (SW18), edited by A. Anagnostou et al., 219-229. Worcestershire: ORSociety.

Van der Zee, D. J., K. Kotiadis, A. Tako, M. Pidd, O. Balci, A. Tolk, and M. Elder. 2010. "Panel Discussion: Education on Conceptual Modeling for Simulation - Challenging the Art." In Proceedings of the 2010 Winter Simulation Conference, edited by B. Johansson et al., 290-304. Piscataway, New Jersey: IEEE.

Van der Zee, D. J., R. J. Brooks, S. Robinson, and K. Kotiadis. 2011. "Conceptual Modelling: Past, Present and Future". In Conceptual Modelling for Discrete-Event Simulation, edited by S. Robinson, R. J. Brooks, K. Kotiadis, and D. J. van der Zee, 473-490. Boca Raton: CRC Press.

Van der Zee, D. J. 2017. “Approaches for Simulation Model Simplification”. In Proceedings of the 2017 Winter Simulation Conference, edited by K. V. Chan et al., 4197-4208. Piscataway, New Jersey: IEEE.

Wang, W., and R. J. Brooks. 2007. "Improving the Understanding of Conceptual Modelling." Journal of Simulation 1(3):153-158.

Yin, H. Y. and Z. N. Zhou. 1989. "Simplification Techniques of Simulation Models." In Proceedings of Beijing International Conference on System Simulation and Scientific Computing, October 23-26, 1989, Beijing, China, edited by W.C. Yuan, 782-786. Beijing : International Academic Publishers.

Zeigler, B. P. 1976. Theory of Modelling and Simulation. Chichester: Wiley.

\section{AUTHOR BIOGRAPHIES}

DURK-JOUKE VAN DER ZEE is Associate Professor of Operations at the Faculty of Economics and Business, University of Groningen, The Netherlands. His research interests include simulation methodology and applications, simulation \& serious gaming, manufacturing planning \& control, and health care operations management. $\mathrm{He}$ is a member of the INFORMS-SIM. His email address is d.j.van.der.zee@rug.nl, and his webpage is www.rug.nl/staff/d.j.van.der.zee.

ANTUELA TAKO is a Reader in Operational Research at the School of Business and Economics, Loughborough University. She holds a $\mathrm{PhD}$ in Simulation and an MSc in Management Science and Operational Research from the University of Warwick. Her research interests include the comparison of simulation approaches (discrete-event simulation and system dynamics), facilitated and participative simulation modelling, conceptual modelling and health care modelling. She is Associate Editor of the Journal of the Operational Research Society. Her email address is a.a.takou@lboro.ac.uk and her webpage is http://www.lboro.ac.uk/departments/sbe/staff/anthi-antuela-tako/.

PAUL FISHWICK is Distinguished University Chair of Arts, Technology and Emerging Communication (ATEC) and Professor of Computer Science (CS), at the University of Texas at Dallas in the United States. He holds a BS in Mathematics from the Pennsylvania State University, an MS in Applied Science from The College of William and Mary. And a PhD in Computer and Information Science from the University of 
Pennsylvania. His research interests are in designing an interdisciplinary approach to modeling. His email address is paul.fishwick@utdallas.edu, and his home page is https://www.utdallas.edu/atec/fishwick/.

STEWART ROBINSON is Professor of Management Science and Dean at the School of Business and Economics, Loughborough University, UK. He holds an honors degree in Management Science (Operational Research) (1985) and a PhD in Management Science (1998), both from Lancaster University. His research interests are in the practices and use of simulation models where he focuses on conceptual modelling, model validation, output analysis and alternative simulation methods (discrete-event, system dynamics and agent based). His email address is s.1.robinson@lboro.ac.uk, and his home page is www.stewartrobinson.co.uk.

OLIVER ROSE holds the Chair for Modeling and Simulation at the Department of Computer Science of the Universität der Bundeswehr, Germany. He received a M.S. degree in applied mathematics and a Ph.D. degree in computer science from Würzburg University, Germany. His research focuses on the operational modeling, analysis and material flow control of complex manufacturing facilities, in particular, semiconductor factories and assembly systems. He is a member of INFORMS Simulation Society, ASIM (German Simulation Society), and GI (German Computer Science Society). Currently, he is member of the board of the ASIM and the ASIM representative at the Board of Directors of the WSC. His email address is oliver.rose@unibw.de. 